Check for updates

Cite this: RSC Adv., 2019, 9, 14974

Received 4th February 2019

Accepted 6th May 2019

DOI: $10.1039 / c 9 r a 00941 h$

rsc.li/rsc-advances

\title{
Preparation of lysozyme-imprinted nanoparticles on polydopamine-modified titanium dioxide using ionic liquid as a stabilizer
}

\author{
Zhongliang Zhao, $\uparrow^{\mathrm{ab}}$ Caihong Zhu, $\uparrow^{\mathrm{a}}$ Qianping Guo, ${ }^{\mathrm{a}}$ Yan Cai, ${ }^{\mathrm{a}}$ Xuesong Zhu ${ }^{\mathrm{a}}$ \\ and Bin Li (iD *ac
}

Molecular imprinting of proteins has evolved into an efficient approach for protein recognition and separation. However, maintaining the structural stability of proteins during the preparation process of molecularly imprinted polymers (MIPs) remains challenging. Ionic liquids (ILs), being capable of maintaining the stability of proteins, might enable effective imprinting and accurate recognition of proteins. In this study, lysozyme (Lyz)-imprinted titanium dioxide $\left(\mathrm{TiO}_{2}\right)$ nanoparticles, $\mathrm{TiO}_{2} \mathrm{QLyz}-\mathrm{MIPs}$, have been successfully prepared for selective recognition and separation of Lyz. This was achieved by the free radical polymerization of hydroxyethyl acrylate (HEA) and poly(ethylene glycol) dimethacrylate (PEGDMA) on polydopamine (PDA)-modified $\mathrm{TiO}_{2}$ nanoparticles using an $\mathrm{IL}$, choline dihydrogen phosphate (chol dhp), as the stabilizer of Lyz. It was found that both PDA modification of $\mathrm{TiO}_{2}$ and the use of chol dhp as stabilizer improved the adsorption capacity of $\mathrm{TiO}_{2}$ (aLyz-MIPs toward Lyz. When the concentration of HEA was $7 \mathrm{mg} \mathrm{mL}^{-1}$, the ratio of monomer to crosslinker was $20: 1$, and the concentration of chol dhp was $12.5 \mathrm{mg} \mathrm{mL}^{-1}$, the highest imprinting factor of 4.40 was achieved. $\mathrm{TiO}_{2}$ (aLyz-MIPs exhibited relatively high adsorption capacity with the maximum adsorption capacity up to $120 \mathrm{mg} \mathrm{g}^{-1}$, which was more than four times higher than that of the non-imprinted polymers (NIPS) counterpart, $\mathrm{TiO}_{2} @$ LLyz-NIPs. The adsorption rate of Lyz by $\mathrm{TiO}_{2} @$ LLyz-MIPs was also much higher than that of $\mathrm{TiO}_{2} @$ Lyz-NIPs. TiO 2 @Lyz-MIPs could successfully separate Lyz from diluted egg white, a complex mixture of proteins. Findings from this study indicate that effective recognition cavities toward Lyz were formed on the surface of Lyz-imprinted $\mathrm{TiO}_{2}$ nanoparticles prepared using $\mathrm{IL}$ as the template stabilizer. This approach may facilitate the development of MIPs for efficient protein recognition and separation.

\section{Introduction}

Molecular imprinting is a technology through which templateshaped cavities are created in polymer matrices during polymerization. It has been used in a variety of applications including sensors, ${ }^{1-3}$ chromatographic separation, ${ }^{4,5}$ and solidphase extraction..$^{6,7}$ However, the imprinting of macromolecules, such as proteins and enzymes, remains challenging due to the large molecular size and complexity of them. Especially, proteins are often denatured and unfolded and lose the conformational flexibility during the preparation of molecularly imprinted polymers (MIPs). ${ }^{8-10}$ Therefore, maintaining the

\footnotetext{
${ }^{a}$ College of Chemistry, Chemical Engineering and Materials Science, Orthopaedic Institute, Medical College, Soochow University, Suzhou, China

${ }^{b}$ Department of Orthopaedics, The First Affiliated Hospital, Medical College, Soochow University, Suzhou, China

${ }^{c}$ China Orthopaedic Regenerative Medicine Group (CORMed), Hangzhou, China. E-mail: binli@suda.edu.cn; Fax: +86-512-6778-1163; Tel: +86-512-6778-1163

$\dagger$ These authors contributed equally to this study.
}

structural stability of protein during MIP preparation is one of the greatest concerns in protein imprinting technology. ${ }^{11}$

Ionic liquids (ILs), a class of organic salts that melt at lowtemperatures, have been used as solvents, monomers, crosslinkers, and templates in MIP synthesis to accelerate the process and improve the selectivity and absorption of the template. ${ }^{12-14}$ In recent years, ILs have been found to stabilize enzymes and proteins,${ }^{15-17}$ partially due to its ability to minimize the surface area of protein that is exposed to the solvent. For example, a biocompatible IL, choline dihydrogen phosphate (chol dhp), which has more "physical" effect than the "chemical" effect on protein structure, was able to dramatically retain the structure and activity of a number of proteins such as cytochrome $c$, Lyz, and ribonuclease A. ${ }^{18-20}$ As a result, chol dhp could help maintain template stability during MIP preparation and resulted in effective imprinting and recognition of proteins. ${ }^{21,22}$

Recently, dopamine (DA), being able to self-polymerizes in aqueous conditions at room temperature, has been increasingly used as the monomer to prepare MIPs for imprinting fragile 
proteins and enzymes in a simple yet highly efficient way. ${ }^{23-25}$ Further, Li et al. ${ }^{26}$ found that MIPs formed by DA selfpolymerization on polydopamine (PDA)-modified silica particles were able to prevent viral infections, while MIPs formed by DA self-polymerization on pure silica particles had no such effect. This may be due to the increased number of amino and catechol groups interacting with greater amounts of functional groups on the surface of virus to form three dimensional imprints, which in turn increased the binding capacity and selectivity of MIPs. However, there are no studies to use polydopamine surface-modified $\mathrm{TiO}_{2}$ nanoparticles as the matrix of protein molecular imprinting.

Over the past 40 years, titanium dioxide $\left(\mathrm{TiO}_{2}\right)$ has been widely applied in photocatalysis for wastewater treatment, in solar cell and electronic devices, as a highly stable, low-cost, and non-toxic material. Recently, due to the appealing characteristics of molecular imprinting, $\mathrm{TiO}_{2}$-based MIPs have attracted increasing attention for its high selectivity and efficient separation potential. ${ }^{27-29}$ In recent, surface molecular imprinting based on nanoparticles has been thought as an effective method to overcome the protein imprinting difficulty in bulk approach, such as large mass transfer resistance and incomplete template removal. Compared to bulk MIPs, surface MIPs based on nanoparticles have extremely higher surface-to-volume ratio due to the small size, the increased surface area helps to provide more recognition sites and enough space for template diffusion. Second, in surface imprinting, the imprinting sites distributed close to the surface layer, resulting in lower mass transfer resistance and faster binding kinetics. ${ }^{30,31}$ So, in this study, $\mathrm{TiO}_{2}$ nanoparticles were used to prepare lysozyme (Lyz)imprinted $\mathrm{TiO}_{2}$ nanoparticles by free radical polymerization of hydroxyethyl acrylate (HEA) and poly(ethylene glycol) dimethacrylate (PEGDMA) on PDA-modified surface of $\mathrm{TiO}_{2}$ using chol dhp to stabilize Lyz templates (Scheme 1). In this approach, PDA surface-modified $\mathrm{TiO}_{2}$ nanoparticles were prepared by DA self-polymerization to improve the interaction between $\mathrm{TiO}_{2}$ and Lyz, which might increase binding capacity and selectivity of $\mathrm{TiO}_{2} @ L y z-M I P s$. On the other hand, Lyz-imprinted nanoparticles were prepared using IL as a protein template stabilizer to ensure that the conformation of Lyz remained intact, which might also result in effective imprinting and recognition of $\mathrm{TiO}_{2} @$ Lyz-MIPs. The molecular imprinting conditions were then optimized by adjusting the feed ratio of monomer, crosslinker and IL. The adsorption behaviors of imprinted $\mathrm{TiO}_{2}$ nanoparticles and their ability to isolate Lyz were evaluated.

\section{Materials and methods}

\subsection{Materials}

Titanium dioxide nanoparticles $\left(\mathrm{TiO}_{2}\right.$, anatase, $\left.60 \mathrm{~nm}\right)$ was obtained from Aladdin. Dopamine hydrochloride was from Sigma-Aldrich. Lysozyme (Lyz; chicken egg white, MW 14.4 $\mathrm{kDa}$ ), bovine serum albumin (BSA; MW $66.4 \mathrm{kDa}$ ), and cytochrome $c$ (cyt $c$; bovine heart, MW $12.4 \mathrm{kDa}$ ) were obtained from Solarbio. Acrylamide (AAm), methylene bisacrylamide (Bis), hydroxyethyl acrylate (HEA), poly(ethylene glycol) dimethacrylate (PEGDMA, MW $750 \mathrm{Da}$ ) were obtained from Alfa Aesar. Ammonium persulfate (APS) was obtained from Sinopharm Chemical Reagent Co., Ltd. $N, N, N^{\prime}, N^{\prime}$-Tetramethylethylenediamine (TEMED) was also obtained from Alfa Aesar. Choline dihydrogen phosphate (chol dhp) of $99.8 \%$ purity was obtained from Shanghai Cheng Jie Chemical Co., Ltd.

\subsection{Preparation of Lyz-imprinted $\mathrm{TiO}_{2}$ nanoparticles}

Lyz-imprinted $\mathrm{TiO}_{2}$ nanoparticles ( $\mathrm{TiO}_{2} @$ @yz-MIPs) were prepared in two steps, as shown in Scheme 1. First, polydopamine-modified $\mathrm{TiO}_{2}$ nanoparticles $\left(\mathrm{PDA}-\mathrm{TiO}_{2}\right)$ were made by mixing $\mathrm{TiO}_{2}$ nanoparticles $(250 \mathrm{mg})$, dopamine hydrochloride $\left(2 \mathrm{mg} \mathrm{mL} \mathrm{m}^{-1}, 10.55 \mathrm{mmol} \mathrm{L}^{-1}\right.$ ), and ammonium persulfate $\left(1.2 \mathrm{mg} \mathrm{mL}^{-1}, 5.26 \mathrm{mmol} \mathrm{L}^{-1}\right)$ in $40 \mathrm{~mL}$ Tris- $\mathrm{HCl}(\mathrm{pH}$ $=8.5,10 \mathrm{mmol} \mathrm{L}^{-1}$ ) under shaking overnight at room temperature. After centrifuging (3000 rpm) and washing three times with deionized water, the $\mathrm{PDA}-\mathrm{TiO}_{2}$ were collected for use. Second, the $\mathrm{PDA}^{-\mathrm{TiO}_{2}}$ were dispersed in $40 \mathrm{~mL}$ of PBS buffer $\left(\mathrm{pH}=7.4,10 \mathrm{mmol} \mathrm{L}{ }^{-1}\right)$, and the Lyz template $\left(1 \mathrm{mg} \mathrm{mL}^{-1}\right.$, $\left.0.07 \mathrm{mmol} \mathrm{L}^{-1}\right)$, the ionic liquid chol dhp stabilizer $(12.5 \mathrm{mg}$ $\left.\mathrm{mL}^{-1}, 62.14 \mathrm{mmol} \mathrm{L}^{-1}\right)$, HEA $\left(10 \mathrm{mg} \mathrm{mL}^{-1}, 86.21 \mathrm{mmol} \mathrm{L}^{-1}\right)$ and PEGDMA (0.5 $\mathrm{mg} \mathrm{mL}^{-1}, 0.67 \mathrm{mmol} \mathrm{L}^{-1}$ ) were added into the solution for preassembly. After $3 \mathrm{~h}$, APS $\left(1.25 \mathrm{mg} \mathrm{mL} \mathrm{m}^{-1}\right.$, $5.48 \mathrm{mmol} \mathrm{L}^{-1}$ ) and $20 \mu \mathrm{L}$ TEMED $\left(0.39 \mathrm{mg} \mathrm{mL}^{-1}, 3.33 \mathrm{mmol}\right.$ $\left.\mathrm{L}^{-1}\right)$ were then added under nitrogen protection to act as the initiator and accelerator, respectively, and the reaction was allowed to proceed for $24 \mathrm{~h}$ with shaking at room temperature. After polymerization, the resultant nanoparticles were washed with deionized water to remove unreacted monomers and oligomers, then washed repeatedly with $5 \%(\mathrm{v} / \mathrm{v})$ acetic acid containing $5 \%(\mathrm{w} / \mathrm{v})$ SDS solution to remove the embedded template. They were then re-washed several times with deionized water to remove any remaining acetic acid and SDS. Finally, $\mathrm{TiO}_{2} @$ Lyz-MIPs was dried by lyophilization for further use. The

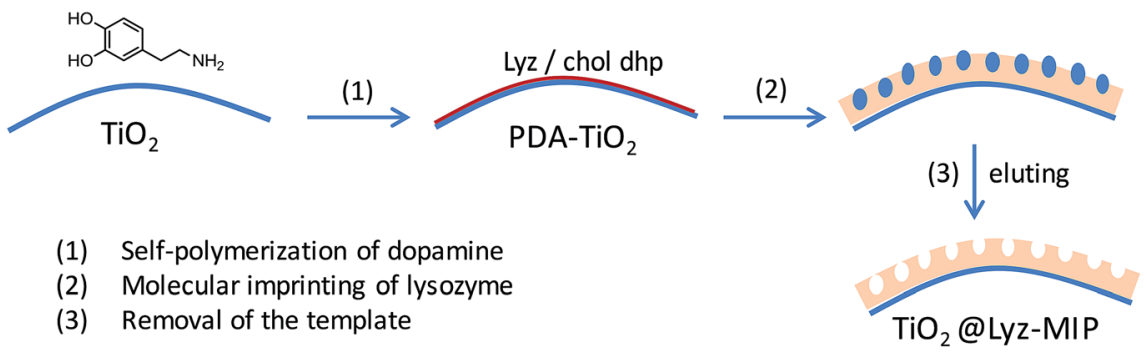

Scheme 1 Preparation of Lyz-imprinted $\mathrm{TiO}_{2}$ nanoparticles ( $\mathrm{TiO}_{2}$ (aLyz-MIPs). 

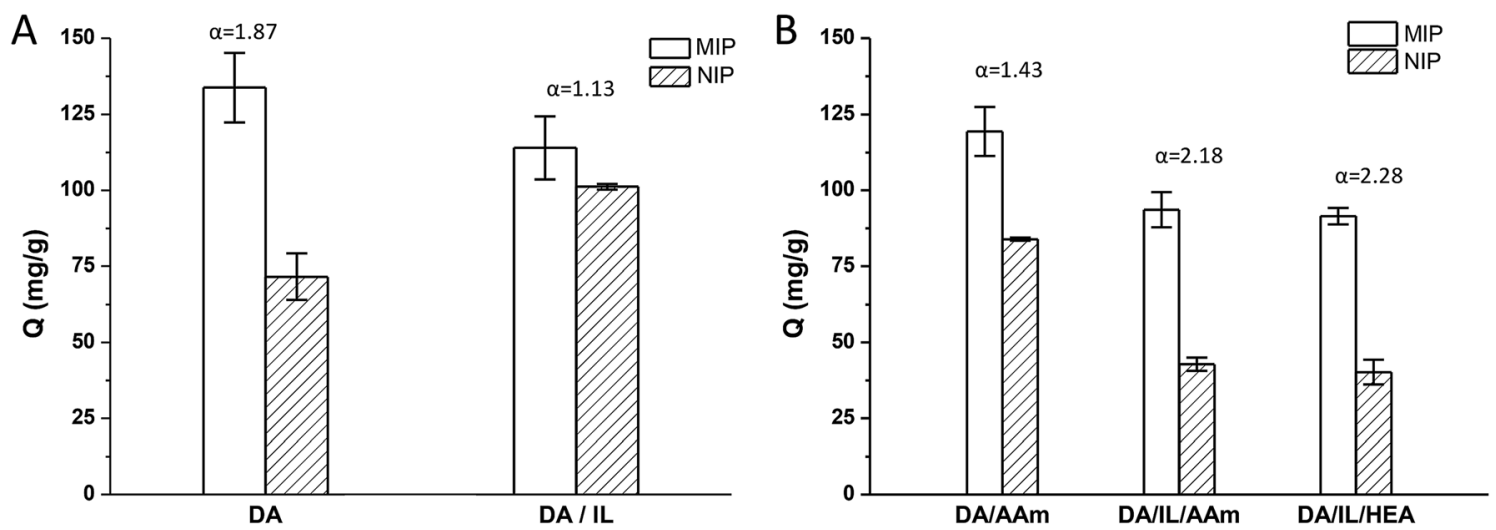

Fig. 1 The effect of various polymerization systems in the preparation of MIPs on their absorption capacity: (A) DA: imprinting by dopamine selfpolymerization on $\mathrm{TiO}_{2}$, DA/IL: Lyz-imprinting by dopamine self-polymerization with chol dhp as stabilizer on TiO ${ }_{2}$; (B) DA/AAm: imprinting by $\mathrm{AAm} /$ Bis radical-polymerization on $\mathrm{PDA}-\mathrm{TiO}_{2}, \mathrm{DA} / \mathrm{IL} / \mathrm{AAm}$ : imprinting by AAm/Bis radical-polymerization with chol dhp as stabilizer on PDA$\mathrm{TiO}_{2}$, DA/IL/HEA: imprinting by HEA/PEGDMA radical-polymerization with chol dhp as stabilizer on $\mathrm{PDA}-\mathrm{TiO} 2\left(\alpha=\mathrm{Q}_{\mathrm{MIP}} / \mathrm{Q}_{\mathrm{NIP}}\right)$. Adsorption condition: $V=10 \mathrm{~mL}, m_{\mathrm{MIP}}=m_{\mathrm{NIP}}=10 \mathrm{mg}, C_{\mathrm{Lyz}}=500 \mu \mathrm{g} \mathrm{mL} \mathrm{m}^{-1}$, in water.

Lyz-non-imprinted $\mathrm{TiO}_{2}$ nanoparticles ( $\left.\mathrm{TiO}_{2} @ L y z-N I P s\right)$ control was prepared the same way and washed following the same procedure in the absence of the template. The detailed morphology of the imprinted nanoparticles was analyzed through scanning electron microscopy (FEI Co., USA). FT-IR spectra of $\mathrm{TiO}_{2}$ NPs, PDA-TiO 2 NPs, and $\mathrm{TiO}_{2} @$ Lyz-MIPs were performed on a Nicolet-6700 system (Thermo Nicolet Co., USA).

\subsection{Adsorption isotherms of $\mathrm{TiO}_{2} @ L y z-M I P s$}

$\mathrm{TiO}_{2} @$ Lyz-MIPs or $\mathrm{TiO}_{2} @ L y z-N I P s(10 \mathrm{mg})$ were incubated in a solution of the protein (varying concentrations, $10 \mathrm{~mL}$ ). After incubation, the solution was separated from $\mathrm{TiO}_{2} @$ @Lz-MIPs or $\mathrm{TiO}_{2} @$ Lyz-NIPs by centrifugation (6000 rpm), and the concentration of the protein in the solution was determined using a UV spectrophotometer. The amount of protein adsorbed on $\mathrm{TiO}_{2} @ L y z-\mathrm{MIPs}$ (or $\mathrm{TiO}_{2} @$ Lyz-NIPs) was calculated according to the following equation

$$
Q=\left(C_{0}-C_{\mathrm{e}}\right) V / m
$$

where $C_{0}\left(\mathrm{mg} \mathrm{mL}^{-1}\right)$ and $C_{\mathrm{e}}\left(\mathrm{mg} \mathrm{mL}^{-1}\right)$ are the initial and final concentrations of the protein solution, respectively; $V(\mathrm{~mL})$ is the volume of the protein solution; and $m(\mathrm{~g})$ is the mass of the polymer.

Adsorption isotherm studies were conducted by incubating the $\mathrm{TiO}_{2} @$ @Lyz-MIPs or TiO $\mathrm{O}_{2} @$ Lyz-NIPs $(10 \mathrm{mg})$ independently in solutions containing different concentrations of Lyz (initial concentration from 30 to $250 \mu \mathrm{g} \mathrm{mL}^{-1}$ ) at room temperature for $6 \mathrm{~h}$. The amount of protein adsorbed by the nanoparticles was determined as described above.

\subsection{Selective adsorption studies of $\mathrm{TiO}_{2} @ L y z-\mathrm{MIPs}$}

The specific recognition property of MIPs was evaluated using the imprinting factor (IF), defined as $\operatorname{IF}(\alpha)=Q_{\mathrm{MIP}} / Q_{\mathrm{NIP}}$ where $Q_{\text {MIP }}$ and $Q_{\text {NIP }}$ are the adsorption capacity of the template of $\mathrm{TiO}_{2} @ L y z-M I P s$ and $\mathrm{TiO}_{2} @ L y z-N I P s$, respectively.

Selectivity of $\mathrm{TiO}_{2} @ L y z-M I P s$ or $\mathrm{TiO}_{2} @ L y z-N I P s$ toward Lyz was evaluated by comparing their ability to absorb the template protein with their ability to absorb the reference proteins. $\mathrm{TiO}_{2} @ L y z-M I P s$ or $\mathrm{TiO}_{2} @ L y z-N I P s(10 \mathrm{mg})$ was placed into a solution $(10 \mathrm{~mL})$ containing the template or reference protein(s) $\left(250 \mu \mathrm{g} \mathrm{mL} \mathrm{m}^{-1}\right)$. The solutions were shaken for $6 \mathrm{~h}$ at room temperature. The amount of protein adsorbed by the polymers was determined by monitoring the UV absorbance.

\subsection{Competitive adsorption studies of $\mathrm{TiO}_{2} @ L y z-M I P s$}

Competitive adsorption experiments for $\mathrm{TiO}_{2}$ @Lyz-MIPs and $\mathrm{TiO}_{2} @$ @yz-NIPs were performed using a mixture of Lyz and BSA (Lyz $175 \mu \mathrm{g} \mathrm{mL}{ }^{-1}$, BSA $175 \mu \mathrm{g} \mathrm{mL}{ }^{-1}$ ) at $25^{\circ} \mathrm{C}$. TiO ${ }_{2}$ @Lyz-MIPs or $\mathrm{TiO}_{2} @$ Lyz-NIPs $(6 \mathrm{mg})$ was placed into the mixed solution (6 $\mathrm{mL}$ ) containing above two proteins (Lyz $175 \mu \mathrm{g} \mathrm{mL}{ }^{-1}$, BSA 175 $\mu \mathrm{g} \mathrm{mL}^{-1}$ ). The solutions were shaken for $6 \mathrm{~h}$ at $25{ }^{\circ} \mathrm{C}$. After centrifugation, the supernatants were characterized using SDS polyacrylamide gel electrophoresis (SDS-PAGE).

\subsection{Separation of Lyz from diluted egg white solution}

The imprinted $\mathrm{TiO}_{2} @ L y z-M I P s$ were then applied in the separation of Lyz from diluted egg white solution. First, the Lyz source was prepared by separating the egg white from a fresh chicken egg and adding it to a PBS buffer to dilute it 32-fold. The mixture was centrifuged (12000 rpm) at $4{ }^{\circ} \mathrm{C}$ for $15 \mathrm{~min}$, after which the supernatant was collected as diluted egg white solution and stored at $4{ }^{\circ} \mathrm{C}$. Second, the egg white solution was incubated with $\mathrm{TiO}_{2} @$ Lyz-MIPs and $\mathrm{TiO}_{2} @ L y z-N I P s$ in an ice bath for $6 \mathrm{~h}$ under gentle shaking, and the supernatants were collected by centrifugation $(12000 \mathrm{rpm})$. Then, the diluted egg white solution and the supernatants were characterized using SDS-PAGE.

\section{Results and discussion}

\subsection{Preparation and characterizations of $\mathrm{TiO}_{2}$ @Lyz-MIPs}

Recently, MIPs prepared by dopamine self-polymerization in aqueous conditions at room temperature were shown to be effective templates for imprinting fragile proteins and 
enzymes. ${ }^{22-24}$ In the present study, we used a similar method to prepare the Lyz-imprinted $\mathrm{TiO}_{2}$ nanoparticles. As shown in Fig. 1A, the imprinting factor was about 1.87. We then tried to use the chol dhp to stabilize the Lyz and hoped to improve the selectivity ability in polydopamine imprinting. However, contrary to expectations, the color of the reaction solution became much lighter, and the imprinting factor decreased to 1.13. This may be due to the formation of hydrogen bonds between phosphates of chol dhp and dopamine, which would inhibit the polymerization of dopamine. ${ }^{32}$

It was reported that imprinted nanoparticles with high adsorption capacity and specific recognition ability could be obtained by radical-induced polymerization of low concentration monomers on vinyl-modified nanoparticles. ${ }^{33,34}$ So, in the following, we would like to combine the advantages of the two methods, using radical-polymerization of low concentration monomers with chol dhp as a stabilizer on polydopaminemodified $\mathrm{TiO}_{2}$ nanoparticles to prepare Lyz-imprinted $\mathrm{TiO}_{2}$ nanoparticles. On one hand, polydopamine-modified $\mathrm{TiO}_{2}$ would increase the interactions between $\mathrm{TiO}_{2}$ with the Lyz which might result in effective imprinting and selectivity of the achieved $\mathrm{TiO}_{2} @ L y z-M I P s ;$ on the other hand, the interactions between Lyz and functional monomer can be minimized by using chol dhp as stabilizer to ensure integrated conformation of Lyz to improve adsorption capacity and recognition ability.

Two polymerization systems were tested in this study including acrylamide/methylene bisacrylamide system (AAm/ Bis) and hydroxyethyl acrylate/poly(ethylene glycol) dimethacrylate system (HEA/PEGDMA). All results were shown in Fig. 1B. The imprinting factor of the Lyz-imprinted $\mathrm{TiO}_{2}$ by AAm/Bis radical-polymerization on $\mathrm{PDA}^{-\mathrm{TiO}_{2}}$ (DA/AAm group) was 1.43, while the imprinting factor of the Lyz-imprinted $\mathrm{TiO}_{2}$ by AAm/Bis radical-polymerization with chol dhp as a stabilizer on $\mathrm{PDA}^{-\mathrm{TiO}_{2}}$ (DA/IL/AAm group) was increased to 2.18, which indicated that chol dhp could maintain Lyz stability and result in effective imprinting during AAm/Bis radical-polymerization of low concentration monomers. The Lyz-imprinted $\mathrm{TiO}_{2}$ by HEA/PEGDMA radical-polymerization were also prepared with chol dhp as a stabilizer on $\mathrm{PDA}^{-\mathrm{TiO}_{2}}$ (DA/IL/HEA group), and the imprinting factor was slightly increased to 2.28 , perhaps due to the lower destabilization effect to the Lyz in HEA/ PEGDMA system than that in AAm/Bis system. ${ }^{18}$
The imprinting capacity of the two groups were not much different, but considering the effect on the stability of the Lyz structure, ${ }^{21}$ HEA/PEGDMA system was selected as the optimal functional monomer and crosslinker to prepare the Lyzimprinted $\mathrm{TiO}_{2}$ nanoparticles, as shown in Scheme 1. First, polydopamine-modified $\mathrm{TiO}_{2}$ nanoparticles were prepared through the self-polymerization of dopamine in Tris buffer (10 $\left.\mathrm{mmol} \mathrm{L}^{-1}, \mathrm{pH}=8.5\right)$. Afterwards, the Lyz-imprinted $\mathrm{TiO}_{2}$ nanoparticles were prepared in PBS buffer by radicalpolymerization of HEA/PEGDMA system with chol dhp as the stabilizer. Many factors during the imprinting procedure would affect the adsorption capacity, and in this study, the effects of different conditions including the feed amounts and the feed ratios of monomer, crosslinker, and the amounts of stabilizer "chol dhp" were investigated on the adsorption capacity of $\mathrm{TiO}_{2} @$ Lyz-MIPs. The detailed preparation conditions and results were given in Table 1 . As listed in Table 1, when the concentration of HEA, PEGDMA, and chol dhp was $10 \mathrm{mg} \mathrm{mL}^{-1}$ (86.21 $\left.\mathrm{mmol} \mathrm{L}^{-1}\right), 0.5 \mathrm{mg} \mathrm{mL} \mathrm{mL}^{-1}\left(0.67 \mathrm{mmol} \mathrm{L}^{-1}\right)$, and $25 \mathrm{mg}$ $\mathrm{mL}^{-1}\left(124.27 \mathrm{mmol} \mathrm{L}^{-1}\right)$ respectively, the adsorption capacity of the $\mathrm{TiO}_{2} @ L y z-M I P s$ (No. 1 in Table 1) was about $91.5 \mathrm{mg} \mathrm{g}^{-1}$, and the impacting factor was 2.28. Then referring to the reaction condition of No. 1 group, we found that the specific recognition properties of $\mathrm{TiO}_{2} @$ Lyz-MIPs could be improved both by increasing the crosslinker concentration listed as No. 2 , decreasing the concentration of ionic liquid listed as No. 3, and decreasing both the concentration of monomer and crosslinker without changing the feed ratio listed as No. 4, respectively. When the concentration of monomer was about $7 \mathrm{mg} \mathrm{mL}$ $\left(60.34 \mathrm{mmol} \mathrm{L}^{-1}\right)$, the ratio of monomer to crosslinker was 20/1, the concentration of chol dhp was about $12.5 \mathrm{mg} \mathrm{mL} \mathrm{m}^{-1}$ (62.14 $\left.\mathrm{mmol} \mathrm{L}^{-1}\right)$, the imprinting factor would be the highest at 4.40. The repeated preparation of $\mathrm{TiO}_{2}$ @Lyz-MIPs (No. 5) was carried out for three times, and the adsorption amounts of $\mathrm{TiO}_{2} @$ Lyz-MIPs were $91.5,86.0,87.3 \mathrm{mg} \mathrm{g}^{-1}$, the adsorption

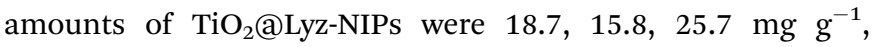
respectively. The results showed that the adsorption amount of Lyz on $\mathrm{TiO}_{2} @ L y z-M I P s$ was stable, and the imprinting factor was also around 4, indicating that $\mathrm{TiO}_{2} @ L y z-M I P s$ had good reproducibility.

The adsorption capacity of $\mathrm{TiO}_{2} @$ Lyz-MIPs (No. 6 in Table 1) imprinted by radical-polymerization of HEA/PEGDMA on pure $\mathrm{TiO}_{2}$ nanoparticles without polydopamine-modification was

Table 1 The effect of various imprinting conditions on absorption capacities of MIPs $^{a}$

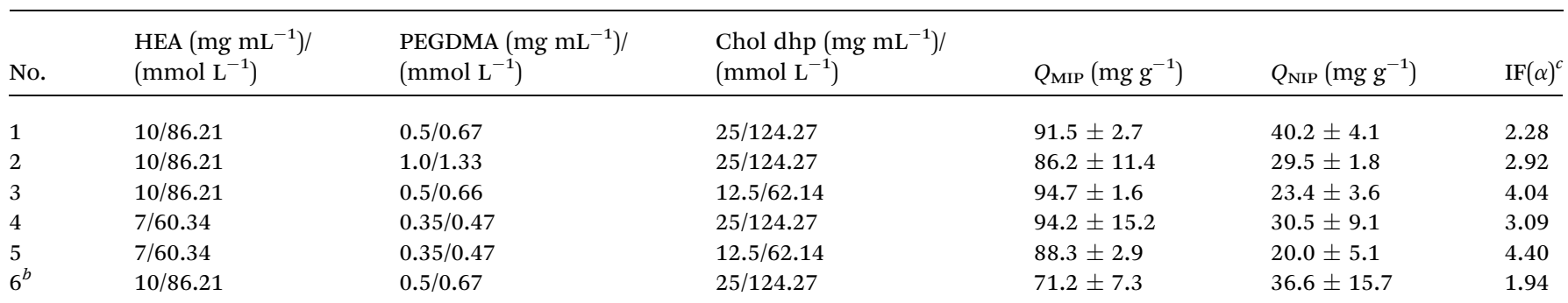

${ }^{a}$ The Lyz concentration of all prepared samples is $1 \mathrm{mg} \mathrm{mL}^{-1}$. The results of each group were obtained from the average adsorption amounts of three parallel samples. ${ }^{b}$ This group was imprinted by radical-polymerization of HEA/PEGDMA on the pure $\operatorname{TiO}_{2}$ nanoparticles. ${ }^{c}{ }^{2} \mathrm{IF}(\alpha): \operatorname{imprinting}$ factor $(\alpha)=Q_{\mathrm{MIP}} / Q_{\mathrm{NIP}}$. 
Table 2 The adsorption capacities of MIPs prepared with different methods

\begin{tabular}{llllll}
\hline Matrix & Template & Monomer & $Q_{\text {MIP }}\left(\mathrm{mg} \mathrm{g}^{-1}\right)$ & $Q_{\text {NIP }}\left(\mathrm{mg} \mathrm{g}^{-1}\right)$ & IF $(\alpha)$ \\
\hline $\mathrm{TiO}_{2} @ P D A$ & Lyz & HEA/PEGDMA & $88.3 \pm 2.9$ & $20.0 \pm 5.1$ & 4.40 \\
$\mathrm{PVP}$ & Lyz & HEA/EGDMA & $43.2 \pm 3.8$ & $18.3 \pm 3.4$ & 2.36 \\
$\mathrm{GO}$ & $\mathrm{AA}$ & HEA & 6.2 & 1.4 & 2.4 \\
$\mathrm{Fe}_{3} \mathrm{O}_{4} @ \mathrm{SiO}_{2}$ & $\mathrm{Lyz}$ & MBA/AAm/MAA & $17.1 \pm 0.4$ & $5.8 \pm 0.3$ & 3.43 \\
$\mathrm{PCL}$ & $\mathrm{Lyz}$ & MAA/DMAEMA & $835 \pm 106$ & $557 \pm 19.6$ & 2.95 \\
\end{tabular}

${ }^{a}$ This work.
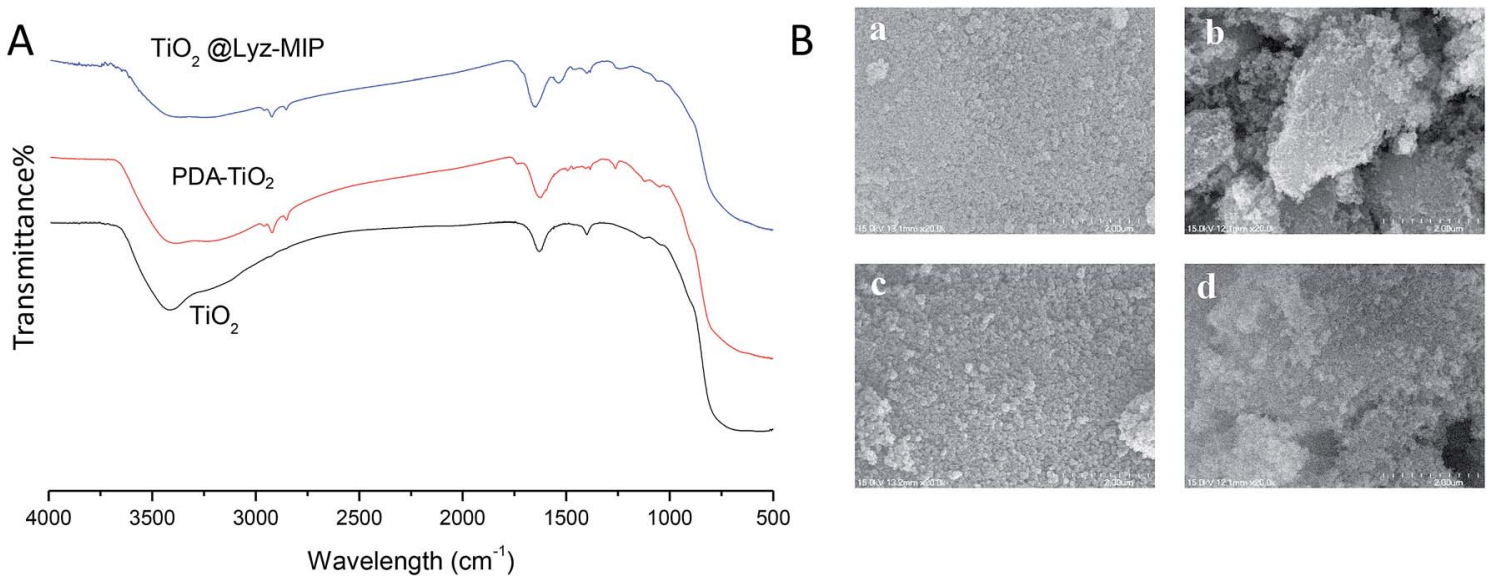

Fig. 2 Characterizations of the imprinted nanoparticles. (A) FT-IR spectra; (B) SEM observations of TiO 2 (a), PDA-TiO 2 (b), TiO 2 (aLyz-MIPs (c) and $\mathrm{TiO}_{2}$ (aLyz-NIPs (d).

tested, and it was found that the imprinting factor was lower than that of the corresponding group (No. 1 in Table 1) prepared by radical-polymerization of HEA/PEGDMA on the $\mathrm{PDA}^{-\mathrm{TiO}_{2}}$ (1.94 vs. 2.28). This demonstrated that polydopaminemodification had a positive effect on the adsorption capacity as expected.

Table 2 compares the adsorption capacities of MIPs prepared on nano/micro-particles with reported different methods. Compared with other MIPs prepared from the same constituent monomers, TiO ${ }_{2} @ L y z-M I P s$ by this new method showed relatively higher adsorption amounts and higher imprinting factor. This may be due to the immobilization of Lyz by PDA layer and the protection of ionic liquids on protein structure.

FT-IR was then used to confirm the successful synthesis of Lyz-imprinted $\mathrm{TiO}_{2}$ nanoparticles. As shown in Fig. 2A, the presence of $\mathrm{PDA}-\mathrm{TiO}_{2}$ was confirmed by the characteristic peaks of $2850-2950 \mathrm{~cm}^{-1}$ assigned to the asymmetric stretching vibration of $\mathrm{O}-\mathrm{H}$ bonds on benzene rings, and the characteristics peaks of $1200-1600 \mathrm{~cm}^{-1}$ were assigned to the bending and shearing vibrations of $\mathrm{N}-\mathrm{H}$ in polydopamine. Furthermore, the observed differences between FT-IR spectra of PDA-TiO ${ }_{2}$ and $\mathrm{TiO}_{2} @$ Lyz-MIPs verified the existence of HEA chains with emergence of peaks at $1534 \mathrm{~cm}^{-1}$. All above results confirmed that $\mathrm{TiO}_{2} @ L y z-M I P s$ were modified onto the titanium dioxide nanoparticles successfully. The morphological studies of $\mathrm{TiO}_{2}$, PDA-TiO ${ }_{2}, \mathrm{TiO}_{2} @ L y z-M I P s$ and $\mathrm{TiO}_{2} @ L y z-N I P s$ was examined by scanning electron microscopy (SEM) (Fig. 2B). Compared to the original $\mathrm{TiO}_{2}$, the PDA-TiO, $\mathrm{TiO}_{2} @$ Lyz-MIPs and $\mathrm{TiO}_{2} @ L y z-$ NIPs showed no apparent increase in size.

\subsection{Adsorption properties of the Lyz-imprinted $\mathrm{TiO}_{2}$ nanoparticles}

During the imprinting process, the template protein molecules were embedded in the polymerization layer, and then after the

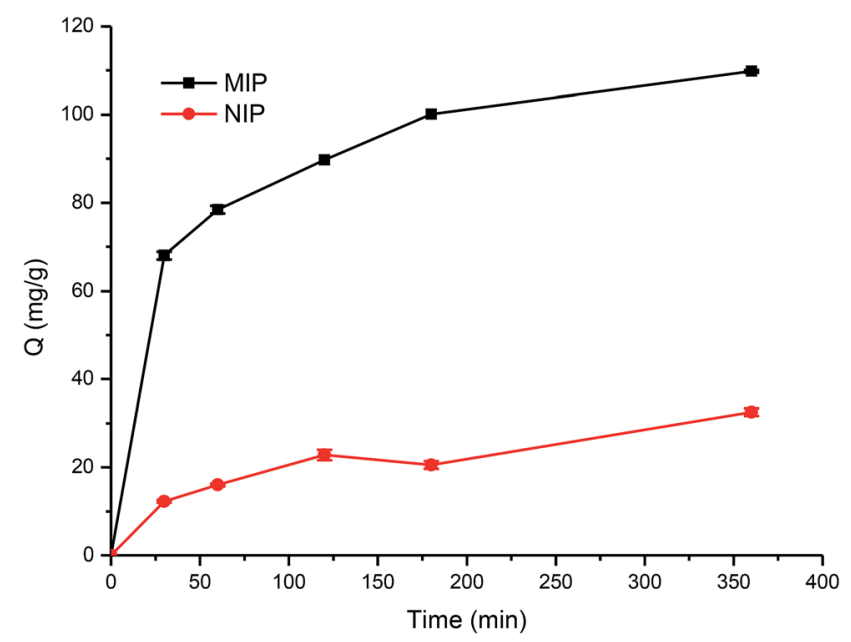

Fig. 3 Absorption kinetic curve of Lyz onto $\mathrm{TiO}_{2}$ @Lyz-MIPs and $\mathrm{TiO}_{2}$ (aLyz-NIPs. Adsorption condition: $\mathrm{V}=10 \mathrm{~mL}, m_{\mathrm{MIP}}=m_{\mathrm{NIP}}=$ $10 \mathrm{mg}, C_{\mathrm{Lyz}}=250 \mu \mathrm{g} \mathrm{mL} \mathrm{H}^{-1}$, in water. 
removal of these embedded protein molecules, the protein imprinted sites would be created. These sites would have a physical shape complementary to the template protein, and consequently can specifically recognize the template protein. ${ }^{38-40}$

In this work, the adsorption kinetics and isotherms of $\mathrm{TiO}_{2} @$ @yz-MIPs (No. 5 in Table 1) and the corresponding $\mathrm{TiO}_{2} @ L y z-N I P s$ were investigated to evaluate the adsorption capacity. As an important consideration in practical application for fast separation, the adsorption kinetics experiment was carried out using $250 \mu \mathrm{g} \mathrm{mL}{ }^{-1}$ Lyz solutions on TiO @Lyz-MIPs and $\mathrm{TiO}_{2} @$ @yz-NIPs at different time intervals. As presented in Fig. 3, the adsorption capacity of both imprinted $\mathrm{TiO}_{2} @ L y z-$ MIPs and non-imprinted $\mathrm{TiO}_{2} @ L y z-N I P s$ rapidly increased in the first $30 \mathrm{~min}$, while the adsorption rate of $\mathrm{TiO}_{2}$ @Lyz-MIPs is much higher than that of $\mathrm{TiO}_{2} @ L y z-N I P s$. This indicated that the interaction force between $\mathrm{TiO}_{2} @$ Lyz-MIPs and Lyz was higher than that between $\mathrm{TiO}_{2} @ L y z-N I P s$ and Lyz, which may be due to the existence of Lyz-shaped imprinted holes on the surface of titanium dioxide. After a period of adsorption, the adsorption rate of both imprinted $\mathrm{TiO}_{2} @ L y z-M I P s$ and nonimprinted $\mathrm{TiO}_{2} @ L y z-N I P s$ was decreased. However, increasing the extraction time still had a small-scale positive trend with adsorption capacity and almost reached equilibrium after $180 \mathrm{~min}$. Adsorption capacity is a key factor to evaluate the selective binding and recognition ability of the imprinting effect on prepared materials. The adsorption isotherms on the

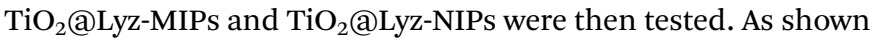
in Fig. 4, TiO ${ }_{2}$ @Lyz-MIPs exhibited relatively higher adsorption capacity than that of $\mathrm{TiO}_{2} @$ Lyz-NIPs within the concentration range covered, suggesting that $\mathrm{TiO}_{2} @ L y z-M I P s$ had specific adsorption. When the initial concentration of Lyz was lower than $30 \mu \mathrm{g} \mathrm{mL} \mathrm{m}^{-1}$, the adsorption capacity gap was very small between $\mathrm{TiO}_{2} @ L y z-$ MIPs and $\mathrm{TiO}_{2} @$ @Ly-NIPs. And the special adsorption became nearly saturated when the concentration was $150 \mu \mathrm{g} \mathrm{mL} \mathrm{m}^{-1}$. The maximum adsorption capacity attained

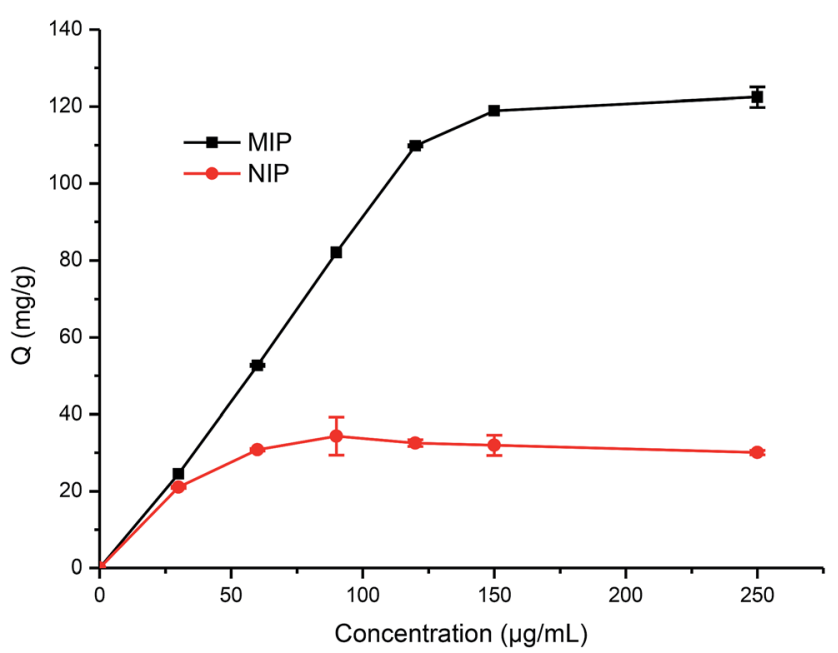

Fig. 4 Absorption isotherm curve of Lyz onto $\mathrm{TiO}_{2}$ (aLyz-MIPs and $\mathrm{TiO}_{2}$ (aLyz-NIPs. Adsorption condition: $V=10 \mathrm{~mL}, m_{\mathrm{MIP}}=m_{\mathrm{NIP}}=$ $10 \mathrm{mg}, C_{\mathrm{Lyz}}=30-250 \mu \mathrm{g} \mathrm{mL}^{-1}$, in water.

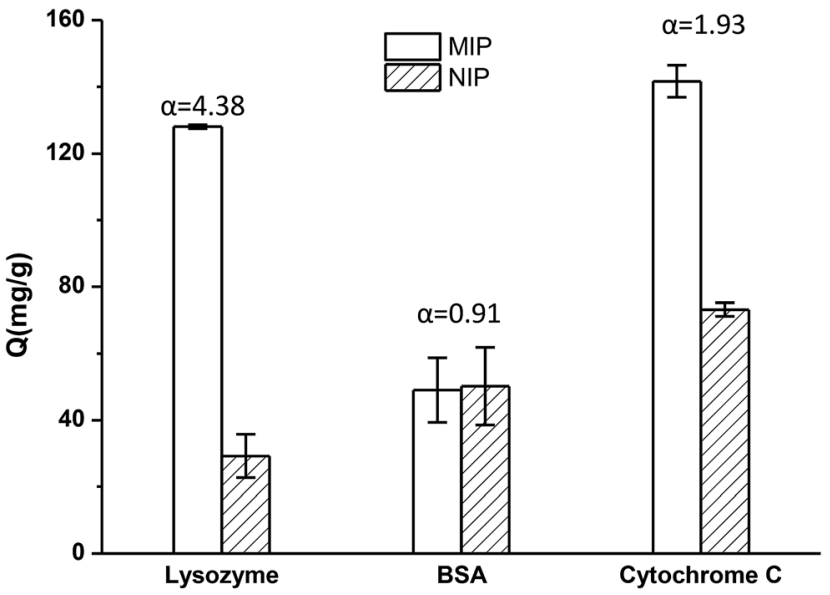

Fig. 5 Amount of different proteins absorbed onto $\mathrm{TiO}_{2}$ (aLyz-MIPs and $\mathrm{TiO}_{2}$ (aLyz-NIPs (imprinting factor $(\alpha)=Q_{\text {MIP }} / Q_{\text {NIP }}$ ). Adsorption condition: $V=10 \mathrm{~mL}, m_{\mathrm{MIP}}=m_{\mathrm{NIP}}=10 \mathrm{mg}, C_{\text {protein }}=250 \mu \mathrm{g} \mathrm{mL}^{-1}$, in water.

from $\mathrm{TiO}_{2} @$ Lyz-MIPs reached the value of about $120 \mathrm{mg} \mathrm{g}^{-1}$, while the maximum adsorption capacity of $\mathrm{TiO}_{2} @ L y z-N I P s$ was about $30 \mathrm{mg} \mathrm{g}^{-1}$. All of this indicated that $\mathrm{TiO}_{2}$ @Lyz-MIPs had relatively high adsorption and the presence of a template in synthesis played a vital role in the formation of imprinted sites on the surface of $\mathrm{TiO}_{2} @ L y z-M I P s$.

The selectivity tests of $\mathrm{TiO}_{2} @ L y z-$ MIPs and $\mathrm{TiO}_{2} @ L y z-N I P s$ were carried out by using BSA and cyt $c$ as the competitor proteins. The initial protein concentration used for binding was $250 \mu \mathrm{g} \mathrm{mL} \mathrm{m}^{-1}$. The experimental result was shown in Fig. 5. From this, we found that the $\mathrm{TiO}_{2}$ @Lyz-MIPs exhibited a much higher imprinting factor of Lyz $\left(\alpha_{\mathrm{Lyz}}=4.38\right)$ with respect to the control $\mathrm{TiO}_{2} @ L y z-N I P s$. The former also exhibited a higher imprinting factor than that of BSA $\left(\alpha_{\mathrm{BSA}}=0.91\right)$ and cyt $c\left(\alpha_{\text {cyt } c}=1.93\right)$. In

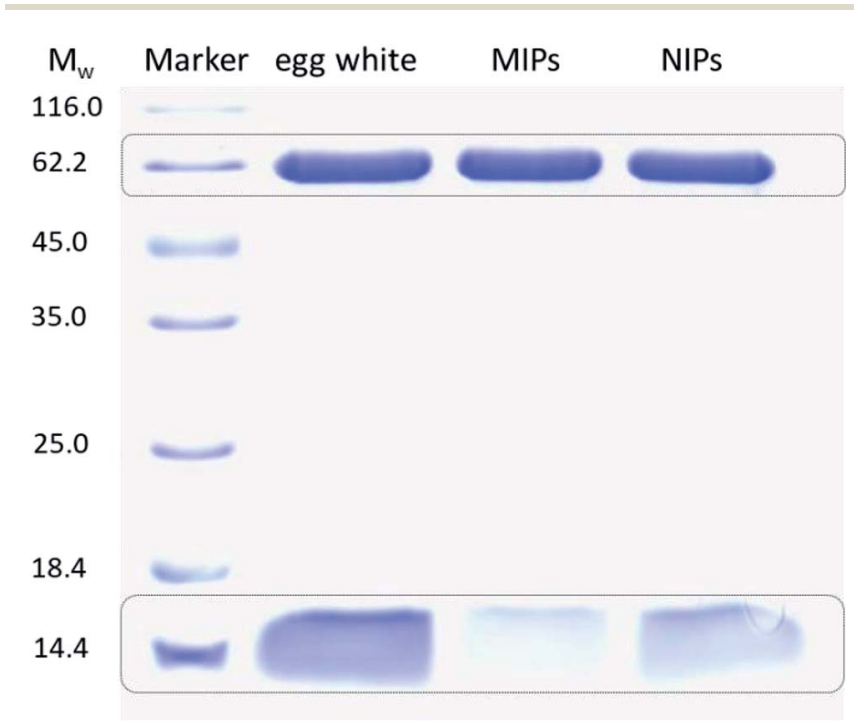

Fig. 6 SDS-PAGE analysis of protein mixture treated with TiO ${ }_{2}$ aLyzMIPs and $\mathrm{TiO}_{2}$ @Lyz-NIPs. Lane 1, protein molecular marker; lane 2, protein mixture (Lyz: $175 \mu \mathrm{g} \mathrm{mL}^{-1}, 14.4 \mathrm{kDa}$; BSA: $175 \mu \mathrm{g} \mathrm{mL}^{-1}, 66.5$ $\mathrm{kDa})$; lane 3, protein mixture after adsorption by $\mathrm{TiO}_{2}$ (aLyz-MIPs; lane 4, protein mixture after adsorption by $\mathrm{TiO}_{2}$ (aLyz-NIPs. 


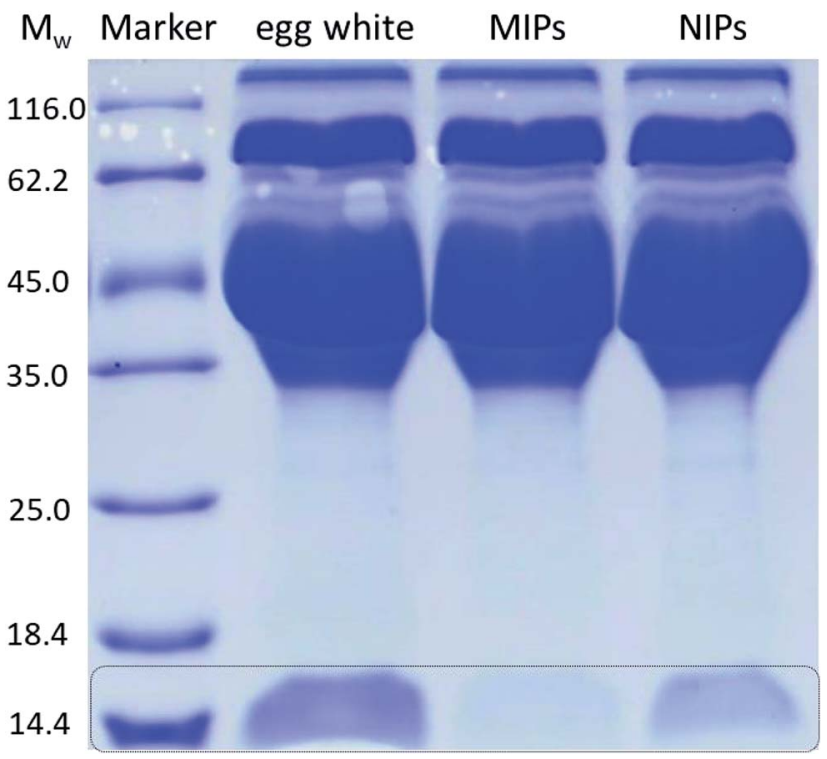

Fig. 7 SDS-PAGE analysis to evaluate the recognition efficacy of $\mathrm{TiO}_{2}$ (aLyz-MIPs towards Lyz. Lane 1, protein molecular marker; lane 2, 32-fold diluted chicken egg white; lane 3, 32-fold diluted chicken egg white after adsorption by $\mathrm{TiO}_{2}$ (aLyz-MIPs; lane 4, 32-fold diluted chicken egg white after adsorption by $\mathrm{TiO}_{2} @$ aLyz-NIPs.

addition, the separation factor $(\beta)$, calculated as $\alpha_{\mathrm{Lyz}} / \alpha_{\mathrm{BSA}}$ and $\alpha_{\text {Lyz }} / \alpha_{\text {cyt } c}$, was 4.81 of BSA and 2.27 of cyt $c$. All of these results indicated that the imprinted $\mathrm{TiO}_{2} @$ Lyz-MIPs had recognition sites on the surface of $\mathrm{TiO}_{2}$ nanoparticles, which were capable of selectively binding Lyz.

To further compare the selectivity of $\mathrm{TiO}_{2} @ L y z-M I P s$ and $\mathrm{TiO}_{2} @ L y z-N I P s$, separation of Lyz from protein mixture (containing $175 \mu \mathrm{g} \mathrm{mL} \mathrm{mL}^{-1} \mathrm{Lyz}$ and $175 \mu \mathrm{g} \mathrm{mL} \mathrm{m}^{-1} \mathrm{BSA}$ ) was performed. The protein mixture after treatment with $\mathrm{TiO}_{2} @ L y z-M I P s$ and $\mathrm{TiO}_{2} @ L y z-N I P s$ was analysed by SDS-PAGE (Fig. 6). The two bands in lane 2 belong to Lyz and BSA, respectively. After treatment with $\mathrm{TiO}_{2} @$ Lyz-MIPs, the band of Lyz disappeared obviously and the band of BSA had little change (lane 3), suggesting most of Lyz was captured by $\mathrm{TiO}_{2} @$ @Lz-MIPs. Different from lane 3, the band of Lyz still could observed in lane 4, indicating $\mathrm{TiO}_{2} @$ Lyz-NIPs had no selectivity toward Lyz.

\subsection{Separation of Lyz from egg white using TiO ${ }_{2} @ L y z-M I P s$}

In order to evaluate the potential use of $\mathrm{TiO}_{2} @ L y z-M I P s$, the separation of Lyz directly from diluted chicken egg white, a sample of complex protein mixture, was tested. The results of the SDS-PAGE were shown in Fig. 7. Compared with the 32-fold diluted egg white samples (lane 2), the intensity of Lyz bands at $M_{\mathrm{w}}$ of $14.4 \mathrm{kDa}$ faded after being treated with $\mathrm{TiO}_{2} @ L y z-M I P s$ (lane 3) and $\mathrm{TiO}_{2}$ @Lyz-NIPs (lane 4). However, the intensity of Lyz bands was much lighter after being treated with $\mathrm{TiO}_{2} @ L y z-$ MIPs compared with that treated with $\mathrm{TiO}_{2} @ L y z-N I P s$, meaning that markedly more Lyz was adsorbed by $\mathrm{TiO}_{2} @$ Lyz-MIPs. This implies that Lyz could be successfully separated from a protein mixture as complex as egg white by $\mathrm{TiO}_{2}$ @Lyz-MIPs. Therefore, $\mathrm{TiO}_{2} @$ @Ly-MIPs may have good imprinting effect and considerable selectivity for actual protein separation applications.

\section{Conclusions}

In this work, an effective surface Lyz imprinted $\mathrm{TiO}_{2} @ L y z-M I P s$ for selective separation of Lyz have been successfully developed by radical-polymerization of HEA/PEGDMA on the polydopamine-modified surface of $\mathrm{TiO}_{2}$ with ionic liquid "chol dhp" as a stabilizer to Lyz. The combination of ionic liquid and surface molecular imprinting technology could overcome the difficulty caused by protein structural variability, and achieve efficient recognition in protein separation process. The molecular imprinting conditions were optimized. It was found that polydopamine-modification would have a positive effect on the adsorption capacity and that using of chol dhp as stabilizer could also result in effective imprinting. When the concentration of HEA was $7 \mathrm{mg} \mathrm{mL}{ }^{-1}\left(60.34 \mathrm{mmol} \mathrm{L}^{-1}\right)$, the ratio of monomer to crosslinker was 20/1, the concentration of chol dhp was $12.5 \mathrm{mg} \mathrm{mL}^{-1}\left(62.14 \mathrm{mmol} \mathrm{L}^{-1}\right)$, the imprinting factor was the highest at 4.40. FT-IR measurement confirmed the successful synthesis of $\mathrm{TiO}_{2} @ L y z-M I P s$. The adsorption capacity of $\mathrm{TiO}_{2} @ L y z-M I P s$ rapidly increased in the first $30 \mathrm{~min}$, meanwhile, the adsorption rate of $\mathrm{TiO}_{2}$ @Lyz-MIPs was much higher than that of $\mathrm{TiO}_{2} @ L y z-N I P s . \mathrm{TiO}_{2} @ L y z-M I P s$ exhibited relatively high adsorption capacity within the concentration range from $30 \mu \mathrm{g} \mathrm{mL} \mathrm{m}^{-1}$ to $250 \mu \mathrm{g} \mathrm{mL} \mathrm{mL}^{-1}$. The maximum adsorption capacity of $\mathrm{TiO}_{2} @$ Lyz-MIPs could reach to $120 \mathrm{mg}$ $\mathrm{g}^{-1}$, which was more than four times higher than that of $\mathrm{TiO}_{2} @$ Lyz-NIPs. The TiO ${ }_{2} @ L y z-M I P s w a s$ also able to separate Lyz from the diluted egg white. All these results demonstrated that recognition cavities have been formed on the surface of $\mathrm{TiO}_{2} @$ @Lyz-MIPs, and this method would propose a good opportunity to promote the development of molecular imprinting technique for protein.

\section{Conflicts of interest}

There are no conflicts to declare.

\section{Acknowledgements}

The authors are grateful to the funding support from the National Natural Science Foundation of China (81471790, 81871805), Jiangsu Provincial Special Program of Medical Science (BL2012004), Jiangsu Provincial Clinical Orthopedic Center, the Priority Academic Program Development (PAPD) of Jiangsu Higher Education Institutions, and the Key Laboratory of Stem Cells and Biomedical Materials of Jiangsu Province and Chinese Ministry of Science and Technology.

\section{Notes and references}

1 Q. Yang, J. H. Li, X. Y. Wang, H. L. Peng, H. Xiong and L. X. Chen, Biosens. Bioelectron., 2018, 112, 54-71.

2 Y. Saylan, F. Yilmaz, E. Ozgur, A. Derazshamshir, H. Yavuz and A. Denizli, Sensors, 2017, 17, e898.

3 M. L. Yola and N. Atar, Curr. Anal. Chem., 2017, 13, 13-17.

4 D. Bitas and V. Samanidou, Molecules, 2018, 23, e316. 
5 M. Rutkowska, J. Plotka-Wasylka, C. Morrison, P. P. Wieczorek, J. Namiesnik and M. Marc, TrAC, Trends Anal. Chem., 2018, 102, 91-102.

6 C. L. Wang, X. L. Hu, P. Guan, D. F. Wu, L. W. Qian, J. Li and R. Y. Song, J. Pharm. Biomed. Anal., 2015, 102, 137-143.

7 X. C. Guo, Z. Y. Xia, H. H. Wang, W. Y. Kang, L. M. Lin, W. Q. Cao, H. W. Zhang and W. H. Zhou, Talanta, 2017, 166, 101-108.

8 K. G. Yang, L. H. Zhang, Z. Liang and Y. K. Zhang, Anal. Bioanal. Chem., 2012, 403, 2173-2183.

9 G. Q. Pan, Q. P. Guo, C. B. Cao, H. L. Yang and B. Li, Soft Matter, 2013, 9, 3840-3850.

10 G. Q. Pan, Q. P. Guo, Y. Ma, H. L. Yang and B. Li, Angew. Chem., Int. Ed., 2013, 52, 6907-6911.

11 L. W. Qian, X. L. Hu, P. Guan, D. Wang, J. Li, C. B. Du, R. Y. Song, C. L. Wang and W. Q. Song, Anal. Chim. Acta, 2015, 884, 97-105.

12 X. M. Zhang, W. M. Yang, N. W. Wang, X. N. Ni, H. J. Wang, Z. Y. Gu, X. Y. Wu and W. Z. Xu, Adv. Polym. Technol., 2017, 36, 220-229.

13 M. Jia, J. Yang, Y. K. Sun, X. Bai, T. Wu, Z. S. Liu and H. A. Aisa, Anal. Bioanal. Chem., 2018, 410, 595-604.

14 R. Viveiros, S. Rebocho and T. Casimiro, Polymers, 2018, 10, e306.

15 Y. Akdogan, M. J. N. Junk and D. Hinderberger, Biomacromolecules, 2011, 12, 1072-1079.

16 T. Vasantha, A. Kumar, P. Attri, P. Venkatesu and R. S. R. Devi, Protein Pept. Lett., 2014, 21, 15-24.

17 M. Bisht and P. Venkatesu, New J. Chem., 2017, 41, 1390213911.

18 K. Fujita, D. R. MacFarlane and M. Forsyth, Chem. Commun., 2005, 4804-4806.

19 K. Fujita and H. Ohno, Biopolymers, 2010, 93, 1093-1099.

20 K. Fujita, K. Murata, M. Masuda, N. Nakamura and H. Ohno, RSC Adv., 2012, 2, 4018-4030.

21 L. W. Qian, X. L. Hu, P. Guan, B. Gao, D. Wang, C. L. Wang, J. Li, C. B. Du and W. Q. Song, Anal. Bioanal. Chem., 2014, 406, 7221-7231.

22 N. Zhang, X. Hu, P. Guan, C. Du, J. Li, L. Qian, X. Zhang, S. Ding and B. Li, Chem. Eng. J., 2017, 317, 356-367.
23 Z. W. Xia, Z. A. Lin, Y. Xiao, L. Wang, J. N. Zheng, H. H. Yang and G. N. Chen, Biosens. Bioelectron., 2013, 47, 120-126.

24 G. D. Riveros, K. Cordova, C. Michiels, H. Verachtert and G. Derdelinckx, Talanta, 2016, 160, 761-767.

25 H. J. Li, X. N. Wang, Z. R. Wang, Y. Wang, J. D. Dai, L. Gao, M. B. Wei, Y. S. Yan and C. X. Li, Microchim. Acta, 2018, 185, e193.

26 N. Li, Y. J. Liu, F. Liu, M. F. Luo, Y. C. Wan, Z. Huang, Q. Liao, F. S. Mei, Z. C. Wang, A. Y. Jin, Y. Shi and B. Lu, Acta Biomater., 2017, 51, 175-183.

27 Y. Liu, J. L. Zhu, X. Liu and H. X. Li, RSC Adv., 2016, 6, 6932669333.

28 J. M. George, A. Antony and B. Mathew, Microchim. Acta, 2018, 185, e358.

29 C. Lai, X. Zhou, D. Huang, G. Zeng, M. Cheng, L. Qin, H. Yi, C. Zhang, P. Xu, C. Zhou, R. Z. Wang and C. Huang, J. Taiwan Inst. Chem. Eng., 2018, 91, 517-531.

30 J. Luo, Q. Ma, W. Wei, Y. Zhu, R. Liu and X. Y. Liu, ACS Appl. Mater. Interfaces, 2016, 8, 21028-21038.

31 J. Wackerlig and R. Schirhagl, Anal. Chem., 2016, 88, 250261.

32 F. Ponzio, P. Bertani and V. Ball, J. Colloid Interface Sci., 2014, 431, 176-179.

33 Y. Liu, Y. Gu, M. Li and Y. Wei, New J. Chem., 2014, 38, 60646072.

34 X. M. Deng, C. Y. Chen, J. F. Xie, C. Q. Cai and X. M. Chen, RSC Adv., 2016, 6, 43223-43227.

35 J. Ji, X. L. Sun, X. M. Tian, Z. J. Li and Y. Z. Zhang, Anal. Lett., 2013, 46, 969-981.

36 Y. X. Wang, Z. H. Chai, Y. J. Sun, M. Gao and G. Q. Fu, J. Biomater. Sci., Polym. Ed., 2015, 26, 644-656.

37 H. R. Culver, S. D. Steichen and N. A. Peppas, Biomacromolecules, 2016, 17, 4045-4053.

38 A. Bossi, F. Bonini, A. P. F. Turner and S. A. Piletsky, Biosens. Bioelectron., 2007, 22, 1131-1137.

39 N. M. Bergmann and N. A. Peppas, Prog. Polym. Sci., 2008, 33, 271-288.

40 L. X. Chen, X. Y. Wang, W. H. Lu, X. Q. Wu and J. H. Li, Chem. Soc. Rev., 2016, 45, 2137-2211. 